\title{
Retraction Note: Coastal atmospheric climate and decoration art design of coastal environment based on GIS
}

\author{
Meilin Meng ${ }^{1}$
}

Published online: 15 November 2021

(c) Saudi Society for Geosciences 2021

Retraction Note to: Arabian Journal of Geosciences (2021) 14: 564 https://doi.org/10.1007/s12517-021-06850-9

The Editor-in-Chief and the Publisher have retracted this article because the content of this article is nonsensical. The peer review process was not carried out in accordance with the Publisher's peer review policy. The author has not responded to correspondence regarding this retraction.

The original article can be found online at https://doi.org/10.1007/ s12517-021-06850-9.

Meilin Meng

mengshengmeng200@163.com

1 School of Arts, Anhui PolytechnicUniversity, Wuhu 241000, Anhui, China 